$\xi=-1$

\title{
Investigation of the Optimal Percentage from Polyvinyl Alcohol on Flexural Strength of Cement Mortar Composite
}

\author{
Waleed A. Abbas ${ }^{1 *}$, Iqbal N. Korkess ${ }^{1}$, Mahdi Jasim H. 1 \\ ${ }^{3}$ Civil Engineering Department, University of Technology, Baghdad, Iraq \\ *Corresponding author E-mail: waleedalqaisi@yahoo.com
}

\begin{abstract}
Polyvinyl alcohol solution(PVA) proveded potential enhancement of the properties of cement mortar composite. This work investigated the effect of $(\mathrm{w} / \mathrm{c})$ and polymer-cement ratios $(\mathrm{p} / \mathrm{c})$ on the flexural strength of type I Portland cement mortar. A sand-cement ratio (s/c) of 1.25 and 0.5 by mass was used, and PVA powder was dispersed in water at $(0.7 \%, 1 \%, 2 \%$, and $3 \%)$ by weight of cement. The p/c solution was adjusted at five different values of $0.008,0.012,0.016,0.020$ and $30 \%$ covering relatively low and high values. Two types of curing were used; wet and dry curing. The study results demonstrated that flexural strength and significant water absorption properties of Portland cement mortar, as well as workability can be basically enhanced by the addition of PVA. Composite was prepared with optimum (p/c) $1.6 \%$ at concentration of $1 \%$ by mass under dry curing. The highest flexural strength was above twice the flexural strength of unmodified mortar. Also modified mortar samples illustrated that increasing of (p/c) causes reducing water absorption due to the packing effect caused by PVA, while mortar prepared at 0.1 and $0.3 \mathrm{w} / \mathrm{c}$ and $(\mathrm{p} / \mathrm{c})$ respectively, exhibited an increase in flexural strength which was more than the strength of unmodified mortar.
\end{abstract}

Keywords: Alcohol, Cement Composite, Flexural Strength, Polyvinyl, p/c.

\section{Introduction}

The most recent couple of decades, producing building material is restricting new experiences with an expansion in the demand with time attributable to limit crude materials, for example, water, limestone, dirt, and others [1]. Thus, this is an ideal opportunity to utilize other substitution materials rather than normal material assets to enhance new remarkable building materials, which won't just build up the limit of basic conduct in spite of the fact that strength is decreased. Therefore, the redesign spending plan can likewise be diminished impressively [2]. The prerequisites to get high quality have been created using full scale deformity free bonds (MDFCs) or concrete polymer composite which were first created and protected by Birchall and his associates in the mid 1980s [2]. In such a sort of composite material, a cooperation among bond and polymer makes a microstructure with unmistakable highlights [3]. The composite likewise called as synthetically fortified earthenware production. The capacity of polymers in composite materials, for example, bond mortar, work with three boss:

-It exhibitions because of the rheological specialist (as coatings on independent bond particles subsequently diminishing bury molecule job).

-Particle pressing as pore filler in spaces between unreacted concrete grains and polymers respond synthetically with the bond hydration items to shape a basic microstructural item referenced to as the cover stage territories [4][5].

-Water dissolvable polymers and watery polymer dispersals are every now and again used to propel the properties of solid, mortar, and bond based composites [6].
Blending the bond blends with these polymer admixtures cause an extensive volume of air voids to frame. The blending strategy was researched to consider the component of air voids creation. The method incorporates pre-wetting the concrete and sand with unadulterated water before totaling the polymer arrangement or dispersal [6].

Cement- polymer composites are materials, which are finished by a little reserve of water driven concrete by polymeric fasteners. Ceaseless research exercises have been utilized to enhance the solidness properties of cement [7]. A portion of the polymers respond artificially with the hydration results of Portland bond, and the others make a film. The earth of the connection subsequently relies on the sort and the amount of polymer utilized. The system of the response isn't completely clear inferable from the undefined idea of the items. Calcium buildings framed by compound association possess the free place in the pore structure. The new mixes hinder the pores, so densifying the structure and refining properties of the concrete glue. The porousness decreases regardless of whether there is no vital decrease in the porosity. Accordingly, the strength properties enhance [8].

The communication among polymer and concrete hydration stages at low w/c proportions is displayed. As quality is an essential interest of each development to make more strong framework. In this way, these materials have gotten huge consideration because of their high flexural and elasticity properties [2]. It is trusted that a portion of the water-solvent polymers collaborate artificially with the hydration results of Portland bond, and the others simply make a film around concrete grains [9] [10]. The capacity of water in polymer-altered concrete blends is vital and hydrating the bond stages as well as in the meantime hydrolysis of polymer, spreading of polymer around concrete particles, and damages rheological 
properties for a fitting functionality. Water is moreover responsible for the aggregate volume and size dispersal of the pore framework creating in the solidified concrete glue [7] [12].

The aftereffects of this investigation demonstrate that flexural quality and critical physical properties of Portland concrete glue with penetrable pore volume and water retention can be altogether enhanced by including of PVA. The investigation settles the vital capacity of w/c-proportion on the achievement of the polymer with the goal that a very low w/c-proportion can even offer invert impact. To achieve the most extreme improvement in the properties of bond mortar, both $\mathrm{p} / \mathrm{c}$ and w/c proportions must be balanced together. Glues arranged at ideal w/c and $\mathrm{p} / \mathrm{c}$ of separately 0.30 and 0.016 showed the most noteworthy flexural quality which was more than double the quality of unmodified glues [7] In spite of its centrality, there are few research interests on bond changing by PVA arrangement and there are not very many works given to concrete mortar-polymer composites.

Flexural quality was estimated and arranged as the most huge mechanical property of the polymer-adjusted concrete mortar and water ingestion was contemplated as the most physical property characterizing the material sturdiness in forceful conditions. The solidified bond glues arranged at the ideal w/c-proportion, i.e. 0.30 , were likewise used to inspect the impacts of $p / c$ on usefulness and mechanical property.

\section{Experimental works}

The cement used was type I Portland cement, it compliances with the requirements of Iraq Standard No.5 (IQS5:1984). The chemical properties of the cement are presented in Table 1 .

\begin{tabular}{|c|c|c|c|}
\hline Composition & Cement (\%) & $\begin{array}{l}\text { Compound Com- } \\
\text { position accord- } \\
\text { ing to Bouge's } \\
\text { equations }\end{array}$ & $\begin{array}{c}\text { Cement } \\
(\%)\end{array}$ \\
\hline $\mathrm{CaO}$ & 61.53 & \multirow{2}{*}{$\mathrm{C}_{3} \mathrm{~S}$} & \multirow{2}{*}{51.03} \\
\hline $\mathrm{SiO}_{2}$ & 20.16 & & \\
\hline $\mathrm{Al}_{2} \mathrm{O}_{3}$ & 4.95 & \multirow{2}{*}{$\mathrm{C}_{2} \mathrm{~S}$} & \multirow{2}{*}{19.30} \\
\hline $\mathrm{Fe}_{2} \mathrm{O}_{3}$ & 3.86 & & \\
\hline $\mathrm{MgO}$ & 1.62 & \multirow{2}{*}{$\mathrm{C}_{3} \mathrm{~A}$} & \multirow{2}{*}{6.59} \\
\hline $\mathrm{SO}_{3}$ & 2.62 & & \\
\hline $\mathrm{K}_{2} \mathrm{O}$ & 0.58 & \multirow{2}{*}{$\mathrm{C}_{4} \mathrm{AF}$} & \multirow{2}{*}{11.75} \\
\hline L.O.I. & 1.63 & & \\
\hline
\end{tabular}

Results indicate that fine aggregate grading is within the rquirments of IQS 45/1984 zone four as shown in Figure 1.

The grading of natural fine aggregate is shown in Figure1. The sand was spread out and left in the air to dry before use. Modified polycarboxylates was applied as a superplasticizer (SP) to control excellent flowability properties of the fresh matrix.

The polymer utilized in this test was (PVA), The synthetic name of PVA (hereinafter now and then additionally alluded to as $\mathrm{PVOH}, \mathrm{POVAL}$ or PVAL) is polyvinyl liquor, as $87-89 \%$ hydrolyzed polyviny1 acetic acid derivation in granular frame. It is viewed as protected to deal with and nonhazardous therefor generally condition well disposed. PVA is a translucent, scentless and dull, White shading in precious stone shape. Compound structure of PVA as appeared in Figure 2.

The PVA powder was dispersed in $300 \mathrm{ml}$ water until the polymer which was then heated to $90^{\circ} \mathrm{C}$ with stirring to completely dissolve the polymer.To prepare PVA solution, about $0.7 \%, 1 \%, 2 \%$, and $3 \%$ of cement weight. The PVA powder (as a concentration limited for each mix) was dispersed in $300 \mathrm{ml}$ of water heated to $90^{\circ} \mathrm{C}$ with stirring to completely dissolve the PVA as shown in
Figure 3. Then the PVA solution was cooled to room temperature and used within $24 \mathrm{~h}$ [10].

The solution was kept overnight in an open-air atmosphere to reduce its volume to an exact value of $100 \mathrm{ml}$. A number of cement-polymer mixes were designed by varying both $\mathrm{p} / \mathrm{c}$ and $\mathrm{w} / \mathrm{c}$ ratios. The $\mathrm{p} / \mathrm{c}$ was adjusted at five different values of $0.008,0.012$ $0.016,0.02$ and 0.30 covering relatively low and high values. Standard specimens were prepared using a planetary mixer specified by ASTM C305-14[12], was used as the standard mixing procedure. Table 2 present the mix proportion of the mixes used, the mixed polymer-modified mortar was cast into molds under very fine vibration to prepare prism specimens of the size $40 \times 40 \times 160 \mathrm{~mm}$. The specimens were demolded approximately 24 hours after casting and then moist cured for two days at $20^{\circ} \mathrm{C}$ and more than $95 \%$ relative humidity, and then 26 days dry curing at $20^{\circ} \mathrm{C}$ and $50-60 \%$ relative humidity. After curing the specimens were used to measure their flexural strength. Flexural strength was determined according to ASTM C 348-14 testing method. The average value of three specimens from each mix was tested. A number of cubes mortar specimens of the size $50 \times 50 \times 50 \mathrm{~mm}$ was also prepared at the constant $\mathrm{w} / \mathrm{c}$ of 0.30 to investigate the effects of polymer on water absorption of hardened cement mortar. These specimens were also cured in the same way. To evaluate the effect of polymer on mortar workability, flow table spread diameter testing method was done according to ASTM C230[13].

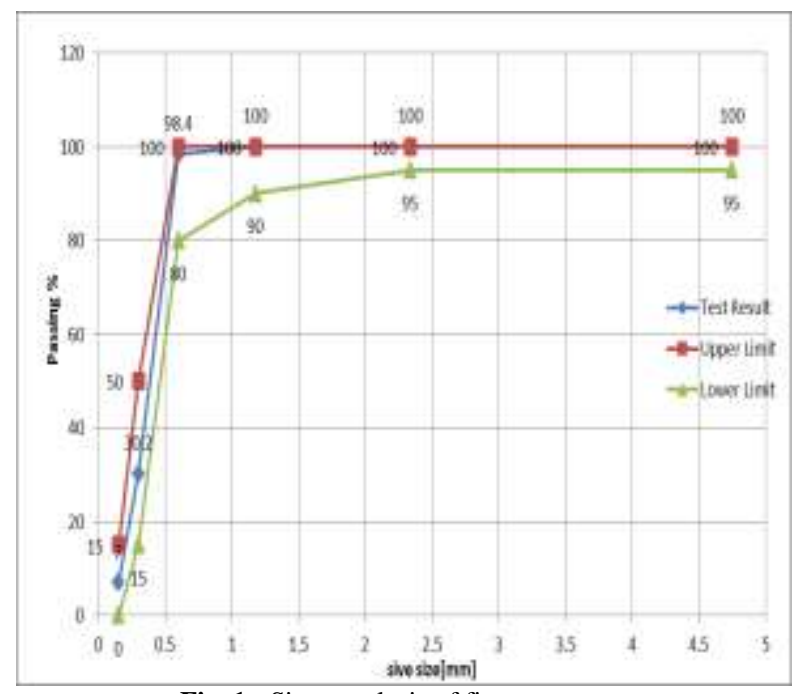

Fig. 1: Sieve analysis of fine aggregate.

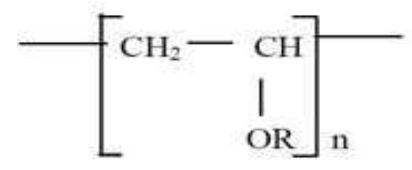

where $\mathrm{R}=\mathrm{H}$ or $\mathrm{COCH}_{3}$

Fig. 2: Chemical structure for Polyvinyl Alcohol [11].

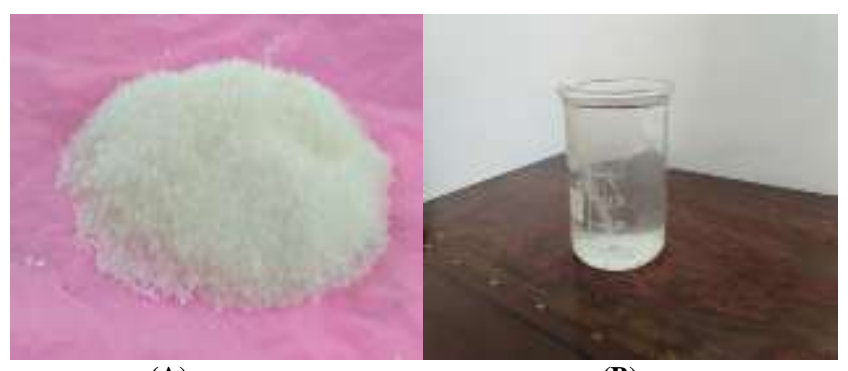

(A)

(B)

Fig. 3: Polyvinyl alcohol (A) powder, (B) after completely dissolved in water. 
Table 2: Mixture proportion used

\begin{tabular}{|c|c|c|c|c|c|}
\hline MIX No. & $\begin{array}{c}\text { Cement } \\
\mathrm{gm}\end{array}$ & $\begin{array}{c}\text { Sand } \\
\mathrm{gm}\end{array}$ & $\begin{array}{c}\mathrm{w} / \mathrm{c} \\
\%\end{array}$ & $\begin{array}{c}\mathrm{p} / \mathrm{c} \\
\%\end{array}$ & $\begin{array}{c}\text { SP* } \\
(\mathrm{ml})\end{array}$ \\
\hline Mix1 & 1000 & 1250 & 0.55 & 0 & 0 \\
\hline Mix2 & 1000 & 500 & 0.45 & 0 & 0 \\
\hline Mix11 & 1000 & 1250 & 0.3 & 0.008 & 20 \\
\hline Mix21 & 1000 & 500 & 0.3 & 0.008 & 5 \\
\hline Mix12 & 1000 & 1250 & 0.3 & 0.012 & 20 \\
\hline Mix22 & 1000 & 500 & 0.3 & 0.012 & 5 \\
\hline Mix13 & 1000 & 1250 & 0.3 & 0.016 & 20 \\
\hline Mix23 & 1000 & 500 & 0.3 & 0.016 & 5 \\
\hline Mix14 & 1000 & 1250 & 0.3 & 0.02 & 20 \\
\hline Mix24 & 1000 & 500 & 0.3 & 0.02 & 5 \\
\hline Mix25 & 1000 & 500 & 0.1 & 0.3 & 5 \\
\hline
\end{tabular}

*SP: superplasticizer

\section{Results and discussions}

\subsection{Workability}

It was indicated that PVA develops the cement mortar workability significantly as shown in the Figures 4 and 5. This influence saws up to a certain limit (at any specified w/c), comparatively greater values of $\mathrm{p} / \mathrm{c}$ act adversely and result in decreased workability. For the two mixtures w/c of 0.30 and 0.1 the limits for $\mathrm{p} / \mathrm{c}$ are 0008 , $0.012,0.016,0.02$ and 0.3 respectively.

The effect of PVA on cement mortar workability is mainly read in terms of improved consistency owing to both the "ball bearing" act and the diffusing influence of PVA. Comparatively greater $\mathrm{p} / \mathrm{c}$, though, decrease the mortar workability because of increases in mortar viscosity. The w/c of the cement mortar at a given consistency (flow) can hence be significantly declined by adjusting it with an appropriate quantity of PVA. This water decrease influence is originated to contribute to a strength progress [14].

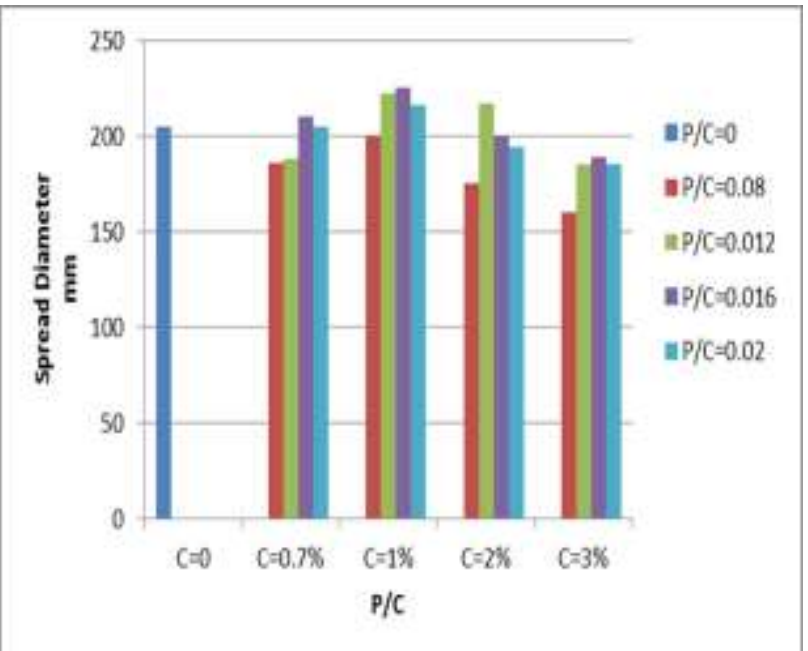

Fig. 4: The spread value of the diameter of the spread cement mortar modified by PVA at different concentration (C=PVA powder $\%$ of cement weight).

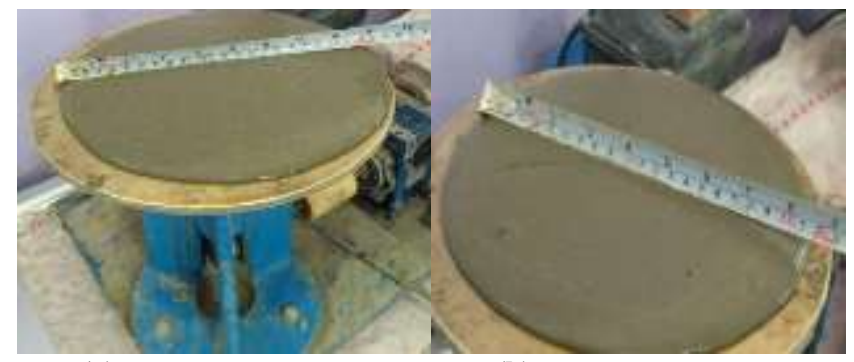

(a)

(b)

Fig. 5: Flowability of (a) unmodified mortar (b) mortar modified with $1 \%$ PVA by mass of cement.

\subsection{Flexural Strength}

The flexural strength (FS) of the samples was taken in agreement with ASTM C 348-14, [15] and using the equation 1.

$\mathbf{F S}=\frac{3 \mathbf{P L}}{2 \mathbf{b d}^{2}}$

In this equation, $\mathrm{P}$ is the maximum applied load, $\mathrm{L}$ is the span length, $b$ is the average width of prisms, and $d$ is the average depth of the prisms. The results are illustrating in figure 6 at the lower w/c of 0.1 adding of not supply any enhancement in flexural strength, but also less value of the flexural strength steadily. Such a reduction in flexural strength is owing to the reasonably low w/c [4].

Moderately lesser quantities of water may not affect in the whole hydrolysis of PVA or an actual diffusion of which around cement grains [14]. Increasing w/c-ratio from 0.1 to 0.30 resulted in significant improvement in addition of polymer. Improvement in flexural strengths particularly at $\mathrm{p} / \mathrm{c}$ around 0.016 with concentration $1 \%$ by cement weight. Figure 7 demonstrates that flexural strength values are increased by increasing the sand content (has maximum size of $0.6 \mathrm{~mm}$ ), which is very similar to results indicated in ref. [16]. Also, the flexural strengths were great as twice the strength of unmodified.

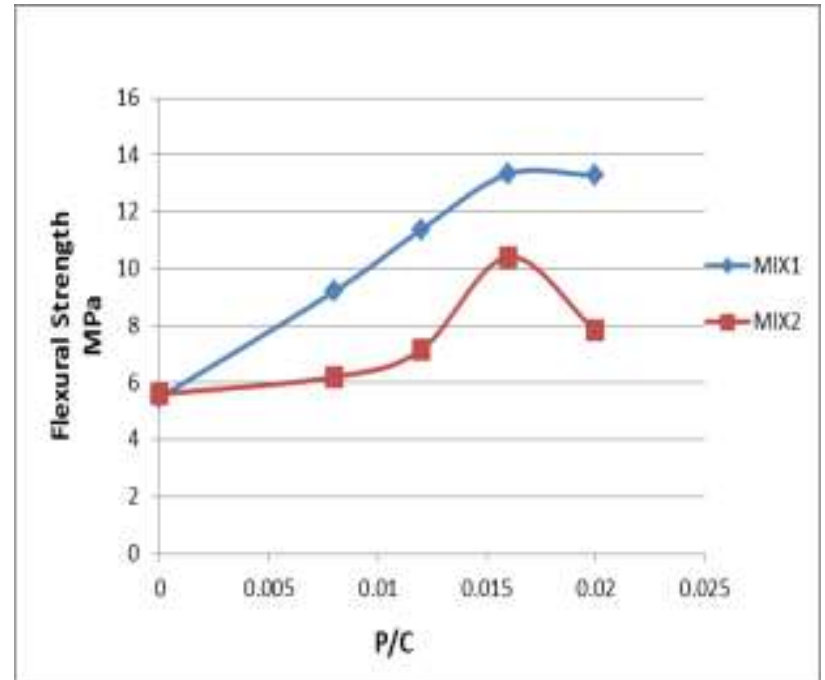

Fig. 6: Flexural strength of cement mortar modified by PVA with different sand/cement and $\mathrm{p} / \mathrm{c}$.

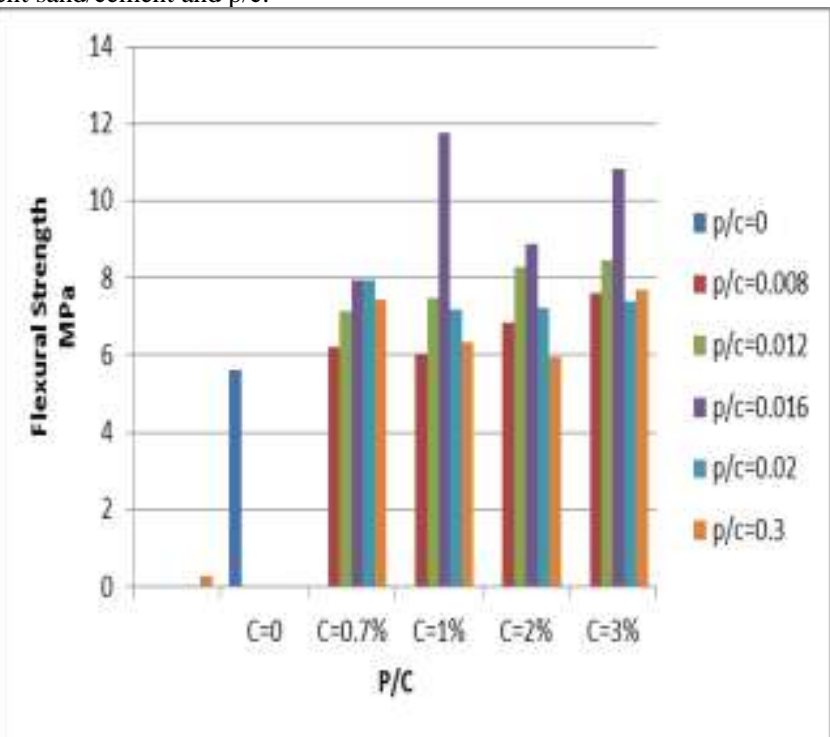

Fig. 7: Flexural strength of cement pastes modified by PVA at different concentration and $\mathrm{p} / \mathrm{c}$. 
Greater w/c, e.g. 0.45 are fewer active on flexural strength. Lesser flexural strengths at reasonably upper w/c-ratio can perhaps be credited to the result of extra water adding making a comparatively great total pore volume in the hardened pastes which deteriorates the flexural performance.

\subsection{Water Absorption}

The capacity of water absorption of cement mortar modified by PVA is hence a simple technique to settle the consequences gotten for total permeable pore volume [7]. The result of PVA totalling on water absorption of hardened cement mortar is presented in Figure 8. It is obvious that water absorption decreases significantly with the rise in p/c. As seen, a 0.02 wt. \% PVA addition can decrease the water absorption to four times of the value obtained from the unmodified mortar. This shows that the PVA addition leads to decrease the porosity of the cement mortar. Additional researches moreover exhibited that the polymer seals the voids in the cement mortar [14]. Polymer-modified cement mortar is so likely to be stronger in the direction of searching destructive situations than reference cement mortar.

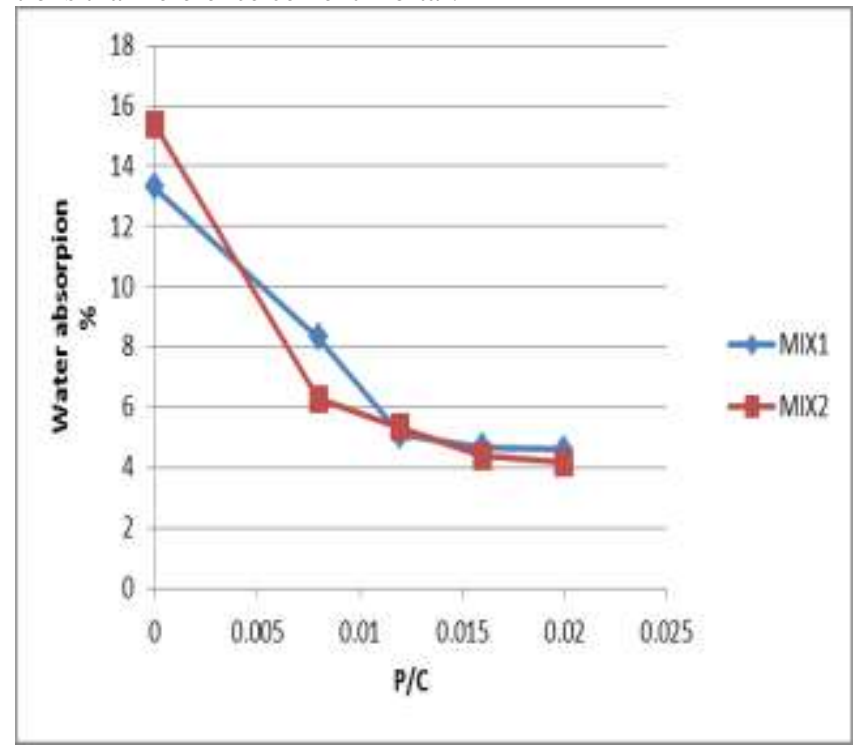

Fig. 8: Effect of PVA addition on water absorption.

\section{Conclusion}

This paper demonstrates the results of an investigational study achieved to improve vision into the act of PVA modified cement mortar and its mechanism.

-The best dosage of PVA that effects the flexural strength was 0.016 with concentration $1 \%$ of cement weight.

-The flexural strength and important physical properties of Portland cement mortar, as well as workability and water absorption, can be markedly improved by the addition of PVA, but the workability decreased with rising $\mathrm{p} / \mathrm{c}$ from the optimum at constant $\mathrm{w} / \mathrm{c}$ equal to 0.3 .

-However, the water absorption gradually declines with increase $\mathrm{p} / \mathrm{c}$ percentage. The dry curing condition very significant to form film polymer which works as reinforcing to cement mortar composite.

-When $\mathrm{p} / \mathrm{c}$ is added as all replacement of $\mathrm{w} / \mathrm{c}$ ratio lead to decrease flexural strength and workability. The study settles the significant character of w/c on the efficiency of the PVA, therefore reasonably low w/c can even arrange for the opposite result. To reach the maximum likely enhancement in properties, both $\mathrm{p} / \mathrm{c}$ and w/c must be optimized together.

\section{References}

[1] S. L. Morissette, J. a Lewis, J. Cesarano, D. B. Dimos, and T. Y. Baer, "Solid freeform fabrication of aqueous alumina-poly (vinyl alcohol) gelcasting suspensions," J. Am. Ceram. Soc., vol. 83, no. 10, pp. 2409-2416, 2000 .

[2] P. Tomar, R. Lakhani, V. K. Chhibber, and R. Kumar, "Macrodefect free cements: a future oriented polymer composite material for construction industries," Compos. Interfaces, vol. 25, no. 5-7, pp. 607-627, 2018

[3] M. Drabik, S. C. Mojumdar, and R. C. T. Slade, "Prospects of novel macro-defect-free cements for the new millennium," Ceram. Silikaty, vol. 46, no. 2, pp. 68-73, 2002.

[4] M. Delucchi and G. Cerisola, "Influence of organic coatings on the stability of macrodefect-free cements exposed to water," Constr. Build. Mater., vol. 15, no. 7, pp. 351-359, 2001.

[5] J. A. Lewis and M. A. Boyer, "Effects of an organotitanate crosslinking additive on the processing and properties of macro-defectfree cement," Adv. Cem. Based Mater., vol. 2, no. 1, pp. 2-7, 1995.

[6] J. Kim and E. Richard, "0 1997," vol. 27, no. 2, pp. 171-176, 1997.

[7] A. Allahverdi, K. Kianpur, and M. R. Moghbeli, "Effect of polyvinyl alcohol on flexural strength and some important physical properties of Portland cement paste," Iran. J. Mater. Sci. Eng., vol. 7, no. 1, pp. 1-6, 2010.

[8] N. B. Singh and S. Rai, "Effect of polyvinyl alcohol on the hydration of cement with rice husk ash," Cem. Concr. Res., vol. 31, no. 2 pp. 239-243, 2001

[9] C. C. Thong, D. C. L. Teo, and C. K. Ng, "Application of polyvinyl alcohol (PVA) in cement-based composite materials: A review of its engineering properties and microstructure behavior," Constr. Build. Mater., vol. 107, pp. 172-180, 2016.

[10] J. Kim, R. E. Robertson, and A. E. Naaman, "Structure and properties of poly (vinyl alcohol) -modified mortar and concrete," vol. 29 , pp. 407-415, 1999

[11] T. Assessment, "Polyvinyl Alcohol (Pva )," Int. J. Toxicol., vol. 1, no. 3, pp. 3-5, 2004.

[12] ASTM, "ASTM C305/2014 - Standard Practice for," Astm, pp. 1-3 2015.

[13] ASTM C230, "Standard Specification for Flow Table for Use in Tests of Hydraulic Cement 1," Annu. B. ASTM Stand., pp. 4-9, 2010.

[14] Y. Ohama, "Polymer-based admixtures," Cem. Concr. Compos., vol. 20, no. 2-3, pp. 189-212, 1998.

[15] ASTM, "ASTM C348. Standard Test Method for Flexural Strength of Hydraulic-Cement Mortars1," Annu. B. ASTM Stand., vol. 04, pp. 2-7, 1998

[16] S. F. U. Ahmed and Y. Y. Lu, "Development of deflectionhardening geopolymer-based ductile fibre reinforced cementitious composites," J. Chinese Adv. Mater. Soc., vol. 1, no. 1, pp. 7-20, 2013. 